Artigos

\title{
Religião, educação e economia em Max Weber
}

\section{Religion, education and the economy in Max Weber}

\author{
Juarez Lopes de Carvalho Filho*
}

\begin{abstract}
Resumo: Este artigo propõe relacionar a religião, a educação e a economia em Max Weber. Apesar de não ter escrito uma obra específica sobre a educação, é possível verificar em escritos como Confucionismo e taoísmo um esboço de tipos ideais da educação encontrados em qualquer sistema de formação, que Weber articulava aos tipos de dominação legitima (racional-legal, tradicional, carismática), seja política seja religiosa. Cada tipo de educação desenvolve nos alunos uma cultura, uma conduta de vida, ou as qualidades que convêm a um tipo de dominação político-religiosa. Esses elementos dos tipos ideais de educação articulados a uma cultura religiosa exercem um papel importante na formação de sistemas econômicos, notadamente de uma cultura capitalista. Como Weber demonstrou na Ética protestante e o "espírito" do capitalismo, existe uma real adaptação, de uma educação religiosa (ascética) ao capitalismo e à sua cultura.
\end{abstract}

Palavras-chave: Educação confucianista. Educação ascética. Cultura capitalista. Conduta de vida.

Abstract: This paper proposes to relate religion, education and the economy in Max Weber. Despite not having a specific written work on education, it is possible to read texts like Confucianism and Taoism as an outline of ideal types of education, present in any training system. Weber has articulated these types of education with the types of (rational-legal, traditional and charismatic) legitimate political as well as religious domination. Each type of education develops in students a culture, a conduct of life, or the qualities befitting a type of political and religious domination. These elements of the ideal types of education articulated a religious culture play an important role in the formation of economic systems, especially in a capitalist culture. As demonstrated in Weber's Protestant ethic and the "spirit" of Capitalism, there is a real adaptation of a religious (ascetic) education to capitalism and its culture.

Keywords: Confucian education. Ascetic education. Capitalist culture. Conduct of life.

* Doutor em Sciences Sociales et Économiques no Institut Catholique de Paris (França), é professor na Universidade Federal do Maranhão em São Luis, MA, Brasil< <juarez.lopes@ gmail.com>.

\begin{tabular}{|c|c|c|c|c|c|}
\hline Civitas & Porto Alegre & v. 14 & n. 3 & p. 540-555 & set.-dez. 2014 \\
\hline
\end{tabular}

A matéria publicada neste periódico é licenciada sob forma de uma 


\section{Introdução}

Este artigo propõe relacionar a religião, a educação e a economia em Max Weber. Nesse sentido, a reflexão se situa ao mesmo tempo no campo da sociologia das religiões, da sociologia da educação e da sociologia econômica. É muito comum falar de uma sociologia das religiões e de uma sociologia econômica desenvolvidas por esse autor. $\mathrm{O}$ mesmo não se pode dizer de uma sociologia da educação, talvez por dois motivos: em primeiro, Weber não escreveu nenhuma obra específica sobre a educação, como foi o caso de Émile Durkheim; em segundo, pelo fato de o texto Confucionismo e taoísmo, no qual Weber esboça uma tipologia da educação, ter ficado muito tempo desvinculado de seu projeto intelectual e científico. Neste texto, Weber relacionou os tipos de educação com os tipos de dominação legitima (racional-legal, tradicional, carismática), seja política seja religiosa, sem deduzir os primeiros dos segundos.

O propósito do texto é demonstrar, na teoria de Weber, como uma religião adquire uma posição de orientação de conduta de vida das camadas socialmente dominantes antes de se tornar um fator de afeiçoamento de uma sociedade. E como numa cultura tradicional, como a chinesa, os determinantes de sua conduta de vida, seu estilo de vida, se impõem para além de seu próprio círculo, até impregnar a sociedade inteira (Grossein, 2000b, p. XVIII).

Apresenta-se inicialmente elementos constitutivos do projeto de uma sociologia das religiões em Weber, reconhecidamente uma das maiores preocupações do sociólogo alemão. Em seguida, expõe-se sua compreensão da ética econômica das religiões mundiais. A relação entre ética econômica das religiões mundiais e a gênese de uma cultura capitalista amplia os horizontes das argumentações de Weber, numa série de comparações a fim de definir a singularidade do capitalismo moderno e do Ocidente. Enquanto a Ética protestante busca as origens do "espírito" do capitalismo no protestantismo ascético (que figura apenas como um elemento causal), a explicação weberiana a partir da ética das religiões se funda em elementos multicausais. Por último, descreve-se a tipologia sociológica da educação esboçada em Confucionismo e taoísmo, colocada em correspondência com os modos de dominação: cada tipo de educação desenvolve nos alunos a cultura, a conduta de vida, as qualidades que convêm a cada tipo de dominação político-religiosa. O projeto de Weber parece ser o mesmo: buscar, pelo viés de uma sociologia histórica e comparada das religiões mundiais, a singularidade da civilização ocidental dominada pelo processo de racionalização crescente. 


\section{Sociologia da religião: uma sociologia da dominação}

A partir das relações entre o protestantismo e o capitalismo, Weber amplia o problema de uma sociologia comparada das religiões, em uma história comparada do capitalismo. Deste último, encontramos elementos essenciais nos estudos de sociologia das religiões. Esses estudos são a continuidade direta do estudo consagrado ao protestantismo. Ou seja, a Ética econômica das religiões mundiais e a Ética protestante e o espirito do capitalismo formam um conjunto coerente que, atualizando os "processos de racionalização religiosa em longo prazo", fornece a chave do desenvolvimento específico da cultura ocidental: o protestantismo constituiria o desfecho do processo de "desencantamento do mundo" inaugurado pelo judaísmo (Grossein, 2000a, p. 78).

A curiosidade histórica de Weber se estendeu a todas as épocas. Ele analisou tanto a ação dos fatores políticos e sociais como dos fatores religiosos, tendo estes um lugar privilegiado nos dispositivos teóricos de seu projeto de uma sociologia histórica e comparativa. De 1911 a 1914, ele se dedica aos esboços de uma sociologia da religião consagrados sobre a ética econômica das religiões universais. A partir de 1916, ele publica seus estudos nos Archiv für Sozialwissenschaft und Sozialpolitik, temendo que suas reflexões não fossem retomadas após a Primeira Guerra. Os artigos deveriam aparecer simultaneamente com Wirtschaft und Gesellschaft contido no Grundriss der Sozialökonomik. Eles eram destinados a explicar e completar a parte consagrada à sociologia da religião. Logo da publicação dessa versão, ainda imperfeita, Weber acrescenta uma Introdução que ele redige em 1915 e na qual ele empreende uma espécie de primeiro resumo provisório dos principais resultados; no mesmo ano ele redige as Considerações intermediárias. Em 1920, antes de morrer, Weber reúne os estudos de sociologia da religião em três volumes intitulados Coletânea de estudos de sociologia das religiões. Para a reedição, Weber rever a Ética protestante e Confucionismo e taoísmo e insere um "Prefácio". Ele fala em termos de uma mise en æeuvre do método aplicado em Ética protestante e na Coletânea de estudos de sociologia das religiões; a análise insiste sobre os efeitos que a religião enquanto sistema de regulamentação da vida exerce sobre a conduta de vida cotidiana das massas.

No início de seus estudos sobre a sociologia da religião, Weber insiste sobre a originalidade dos produtos culturais da idade capitalista; existe nele a ideia de que esses produtos culturais sejam ligados a uma época e a uma estrutura de certo tipo de sociedade. Ele engloba numa visão de conjunto as relações das principais religiões com a economia e a estratificação social de seu universo social. 
No que concerne a sua observação da religião, Weber não se preocupa, como Durkheim, em As formas elementares da vida religiosa, com a busca de uma definição prévia. Em Economia e sociedade, enfatizando a impossibilidade de definir a priori a religião, ele concebe-a como "uma maneira particular do modo de agir em comunidade" (Weber, 1995, p. 145). Weber entende ser necessário analisar as condições e os efeitos de tal comportamento. Nesse sentido, tanto Weber quanto Durkheim rompem com a pretensão fenomenológica de captar uma essência da religião, uma vez que o sociólogo francês define a religião como um dos mais primitivos fenômenos sociais.

Weber, nas suas análises sobre a religião, expõe duas observações que implicam em grandes consequências. A primeira é a seguinte:

As formas mais elementares do comportamento motivado por fatores religiosos ou mágicos são orientadas para o mundo terrestre. Os atos ditados pela religião ou pela magia devem ser realizados 'a fim de se conquistar [...] a felicidade e uma longa vida na terra' (Weber, 1995, p. 145-146).

Para Willaime (2012, p. 50) "essa afirmação representa uma reversão considerável com relação a todas as perspectivas teóricas que identificam interesses religiosos e interesses pelo além a uma falta de distância evidente com o próprio discurso religioso". Para Weber "mesmo através de referências a uma ou outra manifestação do além, a religião diz respeito à vida terrestre" (Weber, 1995, p. 145-146).

A segunda observação é uma ruptura: é que Weber se recusa a associar o religioso ao irracional: "Os atos motivados pela religião ou pela magia são atos, ao menos relativamente, racionais". Segundo Willaime (2012, p. 50), uma das principais contribuições de Weber consiste em mostrar que existem diferentes tipos de racionalidade e que a racionalização da própria religião exerceu um papel fundamental no surgimento da modernidade.

Dois conceitos são importantes para entender a abordagem weberiana da religião: "agrupamento hierocrático" e "bens de redenção". Por agrupamento hierocrático ele entende um grupo no interior do qual se exerce um modo particular de dominação sobre os homens. Em efeito, Weber inscreve sua sociologia das religiões no âmbito de uma sociologia da dominação. Ele observa de modo particular, os modos do exercício do poder religioso. Assim, "um modo de agir em comunidade", é uma forma de dominação sobre os homens. Weber coloca duas principais características da religião 
apreendida como fenômeno social: o vínculo social e o tipo de poder que ela gera. Desse fato, a sociologia da religião weberiana busca definir os tipos de "comunalização religiosa", assim como os tipos de dominação religiosa. Os tipos de comunalização religiosa se apresentam na famosa distinção entre Igreja e "seita", apreendidas como dois modos de existência social da religião. A igreja seria uma instituição burocrática de salvação aberta a todos, na qual é exercida a autoridade de função do padre, que coabita em perfeita simbiose com a sociedade global. A seita seria uma associação voluntária de crentes em ruptura mais ou menos marcada pelo ambiente social. Nesta última forma de associação prevalece uma autoridade religiosa do tipo carismático.

Quanto aos tipos de autoridade religiosa, Weber os elaborou a partir da observação de diferentes formas de legitimação do poder na vida social. A dominação é acompanhada de uma forma legítima, cuja função é normalizar o que está estabelecido. Essa legitimidade é uma crença social que valida o poder exercido pelo dominante. Como sabemos, Weber distingue três tipos de dominação legítima: 1) a dominação tradicional, funda sua legitimidade, sua crença, no caráter sagrado da tradição. Por exemplo: o poder patriarcal no seio dos grupos domésticos, o poder dos senhores na sociedade feudal. 2) a dominação carismática procede de uma personalidade dotada de uma aura excepcional. O chefe carismático funda a crença no seu poder no caráter sagrado, na virtude heroica ou no valor exemplar de sua pessoa. 3) a dominação racional-legal, repousa sua crença na legalidade do direito abstrato e impessoal. O tipo mais exemplar desse tipo de dominação é a "dominação pela direção administrativo-burocrática", cuja submissão é expressa num código (código civil), numa regra universal e funcional.

No campo religioso esses modos de dominação legítima definiriam os tipos ideais do padre, do feiticeiro e do profeta. O padre representaria a autoridade religiosa de função exercida dentro de uma estrutura burocrática de salvação. O feiticeiro a autoridade religiosa que exerce suas competências como autêntico portador de uma tradição junto a uma clientela que o reconhece como tal. E o profeta, a autoridade religiosa pessoal daquele que impõe sua legitimidade por meio de uma revelação que o mesmo divulga. Willaime (2012, p. 55) ressalva que essa tipologia das formas de autoridade religiosa exige uma utilização cuidadosa de seus termos; contudo, seu poder heurístico é grande e muitos sociólogos das religiões referem-se a ela. Ela serve para perceber que as análises de Weber ultrapassam as relações de um ethos do protestantismo puritano e o desenvolvimento de certa racionalidade econômica. 


\section{Religião e ética econômica}

No texto Introdução, referido anteriormente, Weber define o projeto de pesquisa e os conceitos que lhe servirão a elaborar seu estudo sobre a "ética econômica das religiões universais". Ele formula, ainda, alguns de seus resultados provisórios. Por "religiões universais", ele entende as cinco religiões e sistemas de regras de vida condicionadas pela religião que conseguiram reagrupar em torno de uma ideia religiosa ou de uma moral religiosa uma massa de fiéis: o confucionismo, o hinduísmo, o budismo, o cristianismo e o islamismo. Weber acrescenta o judaísmo, por conter "as condições históricas preliminares decisivas para o entendimento do cristianismo e do islamismo e pela sua significação histórica e autônoma para a evolução da moderna ética econômica do Ocidente" (Weber, 1996, p. 331), ainda que o povo judeu tenha sempre constituído uma minoridade, geralmente um povo de párias. Para o cristianismo ele remete aos seus trabalhos sobre a ética protestante.

Convém sublinhar que Weber entende por "ética econômica" não a "teoria moral dos tratados das teologias, que pode servir somente de instrumento de conhecimento, mas as incitações práticas à ação enraizadas nas articulações psicológicas e pragmáticas das religiões" (Weber, 1996, p. 332). Dito de outra maneira, não se trata de expor a teologia moral dessas religiões, mas de compreender os encadeamentos psicológicos e pragmáticos que exerceram um papel importante nas motivações praticas das atividades em geral e na economia, em particular.

Para compreender a ética econômica assim entendida, Weber examina a determinação religiosa do modo de vida das camadas sociais, cujos estilos de vida foram pelo menos predominantemente decisivos para certas religiões (Weber, 1996, p. 333). No entanto, ele afirma que "a ética econômica" não é uma simples "função" de uma forma de organização econômica; e a recíproca também não é verdadeira, ou seja, a ética econômica não marca sem ambiguidade a forma de organização econômica. Assim, o que Weber deixa entender é que os fatores que determinam a conduta de vida é um elemento entre tantos da ética econômica. Em contrapartida ele afirma que

o modo de vida determinado religiosamente é, em si, profundamente influenciado pelos fatores econômicos e políticos que operam dentro de determinados limites geográficos, políticos, sociais e nacionais. Iríamos perder-nos nessas discussões se tentássemos demonstrar essas dependências em toda a singularidade. Só podemos no caso, tentar retirar os elementos diretivos na conduta de vida das camadas sociais que influenciaram mais fortemente a ética prática de suas respectivas religiões. Esses elementos marcaram os aspectos mais 
característicos da ética prática, as características que distinguem uma ética das outras; e, ao mesmo tempo, foram importantes para a respectiva ética econômica (Weber, 1996, p. 333).

Assim, na Introdução, Weber declina as condutas de vida das grandes religiões do mundo: no confucionismo a ética de uma camada de prebendários letrados seculares e mandarins; aquele que não pertence a essa camada culta não conta. A ética do corpo dessa camada determinou a conduta de vida chinesa; o hinduísmo era esposado por uma casta hereditária de letrados cultos que, além de qualquer cargo oficial, exerceram uma espécie de culto ritualista das almas para indivíduos e comunidade. Essa ética religiosa desta camada, segundo ele, determinou o modo de vida chinês, muito além da própria camada. $\mathrm{O}$ budismo se propagou através dos monges mendicantes e itinerantes, estritamente contemplativos e recusando o mundo. Os brâmanes, educados no Veda, formavam, como portadores da tradição, o estamento religioso plenamente aceito. $\mathrm{O}$ islamismo foi, desde suas origens, a religião de guerreiros que queriam conquistar o mundo, uma ordem cavalheiresca de cruzados disciplinados. O judaísmo, após o Exílio, foi a religião de um "povo pária" cívico, e na Idade Média, a religião de intelectuais treinados na literatura e ritual, característica particular do judaísmo. Essa camada representava uma intelligentsia de "pequenos burgueses" racionalistas. O cristianismo, finalmente, começou sua carreira como doutrina de pobres artesãos jornaleiros itinerantes, mas em todos os períodos de sua formação foi sempre uma religião particularmente urbana e essencialmente burguesa.

Após essa descrição, que não chega a ser uma "tipologia" sistemática da religião, Weber se preocupa em levar em conta as lógicas intrínsecas das diversas esferas de atividades: econômicas, políticas, religiosa, estética, e de se respeitar sua coerência interna de um ponto de vista ideal-típico. É nesse sentido que devemos ler suas considerações sobre as relações da religião com as esferas econômica, artística, erótica e científica. Assim, como observa Giddens (2011, p. 233): "a relação entre o conteúdo das crenças religiosas e as formas das atividades econômicas características de uma dada ordem social são muitas vezes indiretas, sofrendo a influência de outras instituições existentes no seio dessa mesma ordem".

De todo modo, é justo afirmar que o ponto de partida dos estudos weberianos de sociologia das religiões é fundado na seguinte questão: em que medida as concepções religiosas influenciaram o comportamento econômico das diversas sociedades? Weber quis demonstrar que as condutas dos homens das diversas sociedades não são inteligíveis senão no quadro da concepção 
geral que esses homens fizeram de suas existências; os dogmas religiosos e sua interpretação são partes constitutivas dessa visão de mundo. É preciso compreendê-los para compreender o comportamento dos indivíduos, dos seus grupos sociais e, notadamente, suas atividades econômicas. Por conseguinte, Weber quis provar que as concepções religiosas revelam, efetivamente, determinadas condutas econômicas, uma das causas de transformações econômicas das sociedades (Aron, 1988, p. 530).

No Prefácio que Weber colocou na abertura da Coletânea de estudos de sociologia das religiões (1920-1921) 1 ele precisa, desde o início, uma das questões fundamentais de sua obra:

[...] qual encadeamento de circunstâncias levou a que o Ocidente precisamente, e apenas ele, tenha visto aparecer sobre seu solo fenômenos culturais que se inscreveram em uma direção de desenvolvimento, que revestiu - pelo menos gostamos de assim pensaruma significação e uma validade universais (Weber, 1996, p. 489).

É no processo sistemático de racionalização da conduta que Weber identifica a especificidade ocidental, e isso em diferentes domínios: a economia, as ciências, direito, a arte, a arquitetura, o estado. Essa noção de racionalidade, que recobre ao mesmo tempo a progressão de uma eficácia (utilizar sistematicamente meios adaptados para obter um fim), uma progressão da coerência lógica dos discursos (racionalidade dos meios intelectuais ou da ciência), uma progressão da racionalidade ética (redação dos mandamentos divinos do judaísmo antigo) que acompanha ao processo de desmagificação do mundo, Weber aplicou, em primeiro lugar à economia. Assim, ele postulava que se existem diferentes formas de capitalismo, é apenas no Ocidente que ele deu o surgimento a um tipo de homem especializado, tendo uma formação específica: empreendedor burguês, definido por certa relação com o trabalho e pela racionalidade de sua atividade econômica (Weber, 1996, p. 492).

Isso posto, Weber reconhece que o ponto mais difícil a apreender é: como certos conteúdos de crenças religiosas condicionaram a gênese de uma "mentalidade econômica", ou seja, o ethos de uma forma de economia, e isso tomando como exemplo relações do ethos econômico moderno com a ética racional do protestantismo ascético" (Weber, 1996, p. 504). Como ele mesmo afirma, ele se ocupa apenas de uma variante da relação causal. Os estudos sobre a Ética econômica das religiões mundiais, percorrendo as relações das

Trata-se de estudos sobre a ética protestante (Ética protestante e o espirito do capitalismo; e As seitas protestantes e o espirito do capitalismo). 
religiões de civilização mais importantes com a economia e a estrutura social que lhes cercam, tentam seguir as duas causalidades o mais longe possível, numa perspectiva histórica, a fim de encontrar os pontos de comparação com o desenvolvimento ocidental (Weber, 1996, p. 504).

Nas Considerações intermediárias que abre a coletânea de estudos de sociologia das religiões, Weber desenvolve uma "teoria dos graus e orientações da rejeição do mundo". Utilizando o procedimento ideal-típico ele se esforça para esclarecer a interrogação "sobre aquilo que motivou o nascimento e o desenvolvimento das éticas religiosas da rejeição do mundo e sobre as direções que elas tomaram; e, por conseguinte, sobre o 'sentido' possível dessa negação" (Weber, 1996, p. 411). Construindo adequadamente os tipos racionais, ele esperava dar uma "contribuição à tipologia e à sociologia do racionalismo". Como ele afirma:

O racional, entendido no sentido de uma coerência lógica ou teleológica de uma tomada de posição teórico-intelectual ou éticoprática, exerce realmente um poder sobre os homens por mais limitado e instável que esse poder seja e tenha sido frente a outras forças da vida histórica (Weber, 1996, p. 412).

Para Weber as interpretações religiosas que foram criadas pelos intelectuais tendo como alvo a racionalidade, foram fortemente submetidas ao imperativo da coerência (Weber, 1996, p. 412).

Em Considerações Weber se dedica, também, a esclarecer a noção de "ascese" e de "mística" que lhe permitem desenvolver uma tipologia da "rejeição ao mundo". Ele distingue, assim, uma ascese aplicada (ascese intramundana) ao mundo e uma ascese fugitiva ao mundo. Ou seja, uma mística orientada para o mundo e uma mística fugaz ao mundo (Weber, 1996, p. 414).

Após esta descrição, Weber expõe o problema da tensão entre a religião e as outras atividades, que o ocupou mais do que qualquer outro problema. As relações de tensão opõem: a religião e o mundo; a religião e a esfera econômica, a religião e o sistema político; a religião e a sexualidade; e a religião e o império do conhecimento intelectual. Para o propósito deste artigo, nos referimos aqui especificamente à tensão com a economia e o domínio do conhecimento.

As tensões com a economia, a segunda tensão apresentada no texto, tomaram diversas formas: oposição aos juros e à usura, defesa da esmola e da vida reduzida às necessidades estritas, hostilidade do comércio que não poderia agradar a Deus (Weber, 1996, p. 422-423). Segundo Weber, 
Toda operação primitiva de influência sobre os espíritos e sobre as divindades, que elas fossem mágicas ou mistagógicas, tiveram interesses especiais. Lutaram pela riqueza, bem como pela vida, saúde, honra, descendência e, possivelmente, melhorias do destino no outro mundo (Weber, 1996, p. 420).

Weber declina alguns exemplos: foi o caso das religiões fenícias e védicas, da religião popular chinesa, do judaísmo e do islamismo antigos. Tal promessa foi também ofertada aos leigos hindu e budista. Em contrapartida, as religiões sublimadas da salvação tiveram relações cada vez mais tensas com a economia racionalizada (Weber, 1996, p. 421).

Como se vê, a rejeição da atividade econômica é marcada de uma parte pela religião institucional, pelo fato de que toda organização institucional necessita de meios materiais e econômicos, o que pode influenciar por sua vez a religiosidade. Dito de outra forma, os conflitos da ética religiosa da fraternidade com a economia impessoal não impede, como Weber afirmava,

[...] o paradoxo de toda ascese racional, ou seja, que ela própria cria a riqueza que ela rejeitava, estendeu a mesma armadilha para os monges de todos os tempos. Em todo lugar, templos e claustros se tornaram eles próprios, por sua vez, lugares de economia racional por excelência (Weber, 1996, p. 422).

E a economia monacal, atesta Weber, é uma economia racional por excelência. Como o ascetismo recai sempre na contradição que faz com que seu caráter racional o leve à acumulação das riquezas, ele explica que a piedade calvinista puritana valorizou religiosamente a atividade econômica e o sucesso material, contribuindo desse modo, defendendo-se a si mesma, para o desenvolvimento de uma lógica econômica que iria dissolver as motivações religiosas que haviam contribuído para fazê-lo surgir.

A outra orientação de rejeição do mundo nas diversas esferas que interessa aqui para o nosso propósito (a última da análise weberiana) é o domínio do conhecimento reflexivo. É com o intelecto que a religião entra em maior tensão. Aí também se pode constatar que em certos períodos da Historia os padres foram os agentes e mesmo os criadores da cultura, quer por constituírem o elemento capaz de ler e escrever, de que precisavam os chefes políticos, quer por deterem uma espécie de monopólio pedagógico. Observa Weber, que quanto mais uma religião abandona seus aspectos mágicos e místicos para se tornar uma "doutrina", mais se desenvolve sob a forma de um conhecimento teológico ou apologético. Entretanto, por sua vez, uma religião acomodada a 
um tipo de conhecimento especulativo puramente metafísico, não é raro que ela considere a pesquisa empírica, notadamente com base nas ciências da natureza, como sendo mais compatível com seus interesses que a filosofia. Ou seja, a religião podia conciliar-se com a metafísica; mas dificilmente pode encontrar um ponto de entendimento com as disciplinas que desencantam o mundo, não somente porque estas se desinteressam em geral do problema da significação, mas porque elas dão origem a uma técnica puramente mecânica e a uma consciência racional dos problemas, de sorte que a religião se vê cada vez mais relegada entre as forças irracionais ou antirracionais, que exigem o "sacrifício do intelecto". As religiões tentaram encontrar o ponto de encontro, afirmando que o conhecimento que lhe é próprio se situa numa outra esfera que o conhecimento puramente científico e que se baseiam muito mais na intuição ou na iluminação carismática do que no raciocínio. Isso não impede que o problema da teodiceia (que muito preocupou Weber e do qual ele trata no final do texto) se apresente sob nova roupagem com o desenvolvimento da cultura no sentido de um progresso e de um aperfeiçoamento da humanidade (Weber, 1996, p. 448).

\section{A religião e tipos sociológicos da educação}

Os trabalhos no campo da sociologia da educação explorando as análises de Weber são ainda muito restritos. ${ }^{2}$ Os que aparecem nesse sentido são de cunho exegético que tentam garimpar nas obras do autor as passagens e a articulação com os grandes temas presentes na sua obra. É importante lembrar que na Reproduction: éléments pour une théorie du système d'enseignement Pierre Bourdieu e Jean-Claude Passeron, em 1970, já se referem às análises weberianas da cultura chinesa, em particular à cultura de letrados, especificamente ao estudo sobre o Confucionismo e o taoísmo, texto no qual Weber expõe os tipos de educação. O interesse de Bourdieu e Passeron é o de construir uma teoria geral dos campos como "estrutura da relação objetiva", estabelecendo uma homologia "estruturais e funcionais". Essa escassez provavelmente se deve primeiro ao fato do autor não ter escrito um texto específico sobre a educação. Segundo, porque, um dos textos em que ele define de maneira breve, mas pertinente, os grandes tipos de educação, Confucionismo e taoísmo, além de mal conhecido, é geralmente desvinculado do seu projeto intelectual e com capítulos separados. ${ }^{3}$

2 Pode-se citar o trabalho de Guy Vincent (2009) e de Nildo Viana (2004).

3 Exemplo do texto Os letrados chineses, que figura no capítulo 16 da coletânea de texto de Max Weber, publicado no Brasil como Ensaios de Sociologia, originalmente publicada em inglês e com organização e introdução de H. H. Gerth e C. Wright Mills. 
Para compreender as referências de Weber sobre a educação, é importante situar esse objeto no conjunto do seu projeto de uma sociologia histórica e comparada das religiões do mundo e as éticas protestantes e o espírito de capitalismo.

Embora não se possa deduzir dos tipos de dominação legítima os tipos de educação, não foi isso que fez Weber; nem pretender que seu propósito fosse estabelecer uma "tipologia sociológica dos objetivos e dos meios pedagógicos", coisa que ele mesmo se preocupou em ressalvar (Weber, 2000, p. 177); sua definição da educação e seus tipos nos ajudam a compreender a teoria da educação esboçada por ele.

O estudo de Weber sobre o Confucionismo e taoísmo faz parte dos três grandes estudos comparativos de sociologia das religiões que ele publicou a partir de 1915 sob o título geral de Ética econômica das religiões mundiais. Os quatro primeiros capítulos de Confucionismo e taoísmo são dedicados às bases sociológicas da China: a cidade, o príncipe e deus; Estado feudal e estado prebendário; Administração e regime agrário; Auto-administração, direito e ausência de relações capitalista. O quinto capítulo Corps de lettrés, ${ }^{4}$ apresenta a longa formação de um sistema de exames, a caráter literário, que dão unicamente acesso ao corpo dos mandarins, ou seja, à classe dos funcionários civis. Como Weber destaca:

Na China, depois de mais de vinte séculos, a posição social foi determinada pela qualificação às funções oficiais mais do que pela posse; uma qualificação que foi estabelecida através de uma formação (Bildung) e, em particular, sancionada pelos exames. A China foi o país que fez da formação literária o critério de estima social, de maneira mais exclusiva do que a Europa na época humanista ou do que, em último lugar, a Alemanha (Weber, 2000, p. 161).

Assim, na China, a classe de letrados sempre foi "a classe dominante". O imperador se dirige a eles como "Senhores". Sua formação é laica, diferentemente do que se passou na Índia (Ibid., p. 162).

Como relembra o sociólogo francês Guy Vincent (2009), foi para explicar o que é esse sistema de formação levando em conta seu método de cons-

\footnotetext{
4 Em português esse capítulo é traduzido por Letrados chineses. Conserva-se aqui a expressão corps de lettrés, da tradução científica francesa de Confucionismo e taoísmo de Catherine Colliot-Thélène em colaboração com Jean-Pierre Grossein, por indicar a constituição de um grupo social, marcado pelo "espírito" do corpo, uma disposição, uma conduta de vida, um habitus, um ethos. Palavras evocadas que perpassam a obra de Weber, no que concerne à educação religiosa e à cultura capitalista.
} 
trução de tipos ideais, que Weber julga indispensável uma tipologia da educação. Ele os caracteriza da seguinte forma:

No domínio dos objetivos da educação os dois polos extremos historicamente foram os seguintes: de um lado, o despertar de um carisma (quer se trate de qualidades heroicas ou de dons mágicos); de outro, a transmissão de uma instrução especializada. $\mathrm{O}$ primeiro corresponde à estrutura carismática, o segundo à estrutura burocrático-racional (moderna) de dominação. Os dois não estão sem conexão ou transição entre si. O herói guerreiro ou o mágico havia igualmente necessidade de uma instrução especializada. [...] Entre esses contrários radicais, encontramos os tipos de educação que querem cultivar nos alunos um tipo determinado de conduta de vida, que ela seja laica ou clerical. Em todos os casos, uma conduta de vida corresponde a um estatuto (ständisch) (Weber, 2000, p. 177).

Apesar de sermos tentados a aplicar essa tipologia aos tipos "puros" de dominação legítima, não foi o que fez Weber. Guy Vincent argumenta que, na Introdução quando Weber (1996) retoma o que havia esboçado em Economia e sociedade e define a dominação (autoridade) carismática, a dominação (autoridade) tradicional, e enfim, a dominação racional-legal, ele indica, a cada vez, exemplo de relação de dominação legítima: o profeta, o chefe de guerra para o primeiro; o pai de família, o marido, o príncipe e seus ministros para o segundo; o agente de um agrupamento burocrático e o cidadão para o terceiro. No entanto, não encontramos o mestre (professor) e o aluno. Nesse sentido, quando Weber se refere à educação, esse problema está sempre ligado às suas análises sobre os agrupamentos de poder político ou hierocrático ou de um sistema econômico (Vincent, 2009, p. 77). Essa consideração serve para evitarmos o atalho apressado da relação entre escola e democracia e a abstração da educação, da autoridade e do poder pedagógico. Vincent alerta para o fato de que a estrutura da tipologia de Weber elaborada de três termos (dois opostos e um intermediário) é histórica, apesar de ser geral. Ou seja, ela engloba todos os sistemas de educação que se pode observar na história, o que é confirmada nos inúmeros exemplos declinados por Weber em Confucionismo e taoísmo. E mais, a tipologia da educação é dita sociológica, na medida em que recobrindo os diferentes aspectos da atividade social (politica, econômica etc.) ela é colocada em relação com os modos de dominação (Vincent, 2009, p. 77-78).

Para Weber, os objetivos de cada tipo de educação devem corresponder a partir dos elementos essenciais desses tipos de dominação. Mas, os tipos de educação são construídos de objetivos e de meios. O exame dos meios mise 
en œuvre em cada tipo de educação permite a Weber melhor caracterizar e detalhar a análise das escolas na China confucianista ou da escola alemã (Vincent, 2009, p. 78). Em Confucionismo e taoísmo (p. 177-178), encontramos um termo chave, ou um conceito, para caracterizar o objetivo de cada tipo de educação: "despertar", "educar", "dar uma educação, uma cultura". O exercício carismático do ascetismo mágico antigo e os julgamentos dos heróis que os feiticeiros e heróis guerreiros aplicavam aos rapazes tentava ajudar o noviço a adquirir uma "nova alma", no sentido animista, e, portanto, a renascer. As tentativas de educação especializada visam a treinar os alunos para que eles adquiram uma aptidão prática às atividades administrativas, quer ela seja no exercício da magistratura, da condução de um escritório, de um atelier, de um laboratório científico ou industrial ou, ainda, no exército disciplinado. Quanto à pedagogia do cultivo (Kultivationspäedagogik), busca educar um tipo de homem culto (Kulturmensch), diferente segundo o ideal da cultura da camada dominante. Isso significa dizer: um homem que tenha uma conduta de vida interior e exterior determinada.

A China confucianista abandona a educação carismática em proveito da aquisição de uma qualificação. Esta consiste na posse de uma cultura literária aprofundada e do modo de pensamento que convém ao homem de qualidade; essa qualidade é mais específica que a conferida aos alunos, no Ocidente, na formação humanista. Da mesma forma que no Ocidente, ela condiciona o acesso às funções dotadas de um poder de comando na administração civil e militar. Ela é controlada e monopolizada pelo poder político, mas ela confere ao mesmo tempo aos alunos a marca de seu pertencimento social ao corpo de "homens cultivados". Isso dito, não havia na China o treinamento especializado e racional que veio a ser completado e, em parte, substituir essa qualificação cultural no Ocidente (Weber, 2000, p. 178-179). Essa espécie de qualificação é adquirida na escola. O sistema de formação comporta três níveis, que por analogia podem ser chamados de primário, secundário e nível superior. A todos os níveis correspondem exames de redação, estilo e domínios das obras dos autores clássicos. Desde o nível médio são exigidas dissertações que demandam capacidade de análises filológica e erudita de um texto. No nível superior, a maior parte dos sujeitos se vincula às questões do imperador que tratam da administração, mas não no mesmo sentido estrito da técnica como a nossa.

Os textos objetos dos exames são textos clássicos. É bom lembrar que Confucio é um letrado. A palavra chinesa que traduzimos por confucionismo significa "doutrina dos letrados". Weber precisa que não existe, na China, uma "religião" autônoma, de racionalização de uma crença popular suscetível de constituir um poder autônomo. Não existe, por consequência, uma 
hierocracia suscetível de concorrer à burocracia. Os textos que estudam aqueles chamados de alunos não são textos sagrados. A filosofia de Confucio é uma sabedoria cuja preocupação principal foi fazer reinar a ordem no estado, formando homens virtuosos. No capítulo que segue (cap. 6), sobre a Orientação confucianista da vida, Weber acentua o caráter intramundano do confucionismo e a ausência de metafísica nessa doutrina. Essa doutrina intramundana se opõe às religiões da salvação para o "au-delà du monde", mesmo quando se trata do puritanismo.

Weber sublinha, ainda, as diferenças da compreensão da educação na Grécia antiga e no puritanismo. Com isso ele pretende demonstrar que o estudo dos textos antigos canonizados, a relação com os textos escritos como foi praticado na educação confucianista impede de pensar por si mesmo. A razão própria do confucionismo diz respeito a um racionalismo da ordem.

\section{Considerações finais}

Os temas religião, educação (expressa nas fórmulas habitus, disposição, conduta de vida) e economia se encontram com muita frequência no conjunto da obra de Weber, no projeto de elaboração de uma sociologia comparada das religiões presente nos estudos históricos da ética econômica das religiões mundiais, que se apresenta como continuação do estudo consagrado à ética protestante. Como observa Colliot-Thélène (2006, p. 85-86) habitus, "espírito", disposição, são empregados de modo idêntico; designam geralmente o substrato mental das condutas sociais, pelo qual é preciso entender a disposição a se comportar de maneira determinada. Weber explica que o termo "espírito" no "espírito do capitalismo" tem a mesma significação.

Seu objetivo era justificar um dos aspectos da relação causal, a saber, as maneiras pelas quais certas crenças religiosas determinadas condicionam o ethos de uma forma econômica. Em relação a uma maior proporção de protestantes detentores de capitais, ele reconhece explicitamente que é por razões históricas junto às quais o pertencimento confessional aparece como causa primeira dos fenômenos econômicos, mas, até certo ponto, como sua consequência. $\mathrm{O}$ propósito de Weber não era mostrar que o protestantismo engendrou o capitalismo moderno, mas demonstrar as afinidades existentes entre um certo tipo de protestantismo, notadamente o calvinismo puritano e o espírito empresarial.

\section{Referências}

ARON, Raymond. Les étapes de la pensée sociologique. Paris: Gallimard, 1998.

BOURDIEU, Pierre; PASSERON, Jean-Claude. La reproduction: éléments pour une théorie du système d'enseignement. Paris: Minuit, 1999. 
CALLIOT-THÉLÈNE, Catherine. La sociologie de Max Weber. Paris: La Découverte, 2006.

GIDDENS, Anthony. Capitalismo e moderna teoria social. Lisboa: Editorial Presença, 2011.

GROSSEIN, Jean-Pierre. Présentation. In: Max Weber. Sociologie des religion. Gallimard: Paris, 2000a. p. 51-129.

GROSSEIN, Jean-Pierre. Présentation. In: Max Weber. Confucianisme et taoïsme. Gallimard: Paris, 2000b. p. I-XXV.

PASSERON, Jean Claude. Introduction à Max Weber. In: Max Weber. Sociologie des religions. Paris: Gallimard, 1996. p. 1-49.

VIANA, Nildo. Weber: tipos de educação e educação burocrática. Guanicus, v. 1, p. 117-132, 2004.

VINCENT, Guy. Les types sociologiques d'éducation selon Max Weber. Revue Française de Pédagogie, v. 168, p. 75-82, 2009 <http://rfp.revues.org/1755\#text> (5 jan. 2014).

WEBER, Max. Confucianisme et taoïsme. Paris: Gallimard, 2000.

WEBER, Max. Sociologie des religions. Paris: Gallimard, 1996.

WEBER, Max. L'Étique protestante et l' “esprit”' du capitalisme: suivi d'autres essais. Paris: Gallimard, 2003.

WEBER, Max. Ensaios de sociologia. Rio de Janeiro: Guanabara, 1982.

WEBER, Max. Économie e société. v. 1. Paris: Plon, 1995.

WILLAIME, Jean-Paul. Sociologia das religiões. São Paulo: Unesp, 2012.

Autor correspondente:

Juarez Lopes de Carvalho Filho

Av. dos Portugueses $s / n^{\circ}$, bloco 6 , sala 3

Campus do Bacanga

65085-580 São Luis, MA, Brasil

Recebido em: 24 abr. 2014

Aprovado em: 26 jun. 2014 